\title{
Influence of vehicle emissions on the male generative system of Aesculus hippocastanum L.
}

\author{
Evelina Ibragimova ${ }^{1, *}$ and Olga Manankova ${ }^{1}$ \\ ${ }^{1}$ Crimean Engineering and Pedagogical University named after Fevzi Yakubov, Department of \\ Biology, Ecology and Life Safety, 295015, Simferopol, Russia
}

\begin{abstract}
The article presents the results of a study of the impact of vehicle emissions on populations of Aesculus hippocastanum L. growing along roads with different traffic intensities. It was found that in areas of heavy vehicle traffic there is an increased level of abortive pollen production. Plant populations increasing the formation of damaged gametes with increasing anthropogenic load on phytocoenoses can be used for phytoindication of the environmental pollution degree. In areas with heavy traffic, pollutants have an average toxic effect on the gametogenesis of Aesculus hippocastanum L. The quality and degree of damage to the pollen zone formed by plants can serve as a bio-test of the mutagenic effect of environmental factors that have a modifying effect on male gametophyte of higher plants.
\end{abstract}

\section{Relevance of research}

Each year there is a growing anthropogenic impact on the natural environment due to the rapid development of modern technologies. The highest level of technogenic pressure is established in large modern cities, where on relatively small areas there is a high concentration of population, transport and industrial enterprises, leading to the formation of anthropogenic landscapes far from the status of ecological balance. So, in urbanized ecosystems, representatives of biota, including people, facing increased content of pollution of various origins in the environment.

In large industrial centers, emissions from factories and traffic are a major source of environmental pollution. Particular harm is caused by transport vehicles whose exhaust give major part of lead, tire wear - zinc, diesel engines - cadmium, and also $\mathrm{Cu}, \mathrm{Cr}, \mathrm{Ni}, \mathrm{Co}$, $\mathrm{Hg}$, As, Mn [1]. These heavy metals are dangerous pollutants, cumulated in the roadside zone of highways and subsequently included in the circulation of substances in ecosystems, having a negative impact on living organisms, including man [2]. In addition to heavy metals with exhaust, about 300 harmful substances enter the environment, among which carbon oxides, hydrocarbons (carcinogenic benzopyrenes and benzantracenes, formaldehyde, benzene), nitrogen oxides, soot, sulfur dioxide, aldehydes are particularly dangerous $[3,4]$. Progressive accumulation of these compounds in the environment can

* Corresponding author: evelina_biol@mail.ru 
lead to undesirable environmental and social consequences, in this regard, it is very important to assess the quality of the environment at the entry of technogenic pollutants.

The problem of environmental pollution with various ecotoxicants has recently become more acute in the Crimea, where the prevalence the large amount of transport, as well as increasing traffic flow during the holiday season.

To assess the quality of the natural environment in the process of entering the pollutants can be through the response of living organisms, namely through the use of bioindication methods. These methods have proved positive in studying the effects of environmental pollution on the plant component of ecosystems.

\section{Materials and methods}

Since one of the most sensitive systems in a living organism is the reproductive one, the plant reproductive organs can be used in scientific research and experiments as biomonitors for the action of various pollutants in terms of their gametocidal effect on a plant organism [5]. Violations in pollen development can occur both at early stages, in meiosis, and at later stages - at generative cell division and sperm formation [6], therefore, sterility is associated with violations in sporogenesis and gametogenesis [7] and can serve as an indirect indicator of these violations. In this regard, the purpose of this study was to estimate the impact of motor vehicle emissions on the generative organs of higher plants growing along highways with different intensity of motor traffic.

Populations of Aesculus hippocastanum L. were selected as the object of the study. Generative organs (inflorescences) collected from trees growing in anthropogenic zones (variant 1 - heavy traffic, variant 2 - heaviest traffic) served as the material for the study. Generative organs collected from plants of ecologically clean zone served as a control variant. Fertility of pollen grains was determined by iodine method on temporary pressure preparations [8]. Sterility test of male gametophyte was used to screen the palynotoxic effect of motor vehicle emissions. Palynotoxic effects of motor transport emissions were identified by analyzing the frequency of occurrence of different types of pollen grains anomalies (palynomorphological assessment) [5]. The following parameters were considered: the number of fertile and sterile pollen grains, the percentage of cells with abnormalities, calculated from the total number of gametes produced by the generative organs; sterility index (IS), which is a value that shows how many times the frequency of induced sterility level caused by the action of polluetants, above the level of spontaneous sterility (control). On the basis of the pollen fertility indices, test plants calculated the palynotoxic effect of motor vehicle emissions - (PE, \%) [9].

\section{Results and discussion}

The results of the study showed that the populations of Aesculus hippocastanum L. have significant differences in pollen sterility. Table 1 shows the sterility of pollen grains of plants growing in the control zone and along highways with different traffic intensity. 
Table 1. Comparative indicators of pollen sterility of plants growing in the control zone and along motorways with different traffic intensity

\begin{tabular}{|c|c|c|c|c|c|c|c|c|}
\hline \multirow{2}{*}{$№$} & $\begin{array}{c}\text { Version } \\
\text { of the } \\
\text { study }\end{array}$ & $\mathrm{n}$ & \multicolumn{3}{|c|}{ Fertility pollen } & \multicolumn{3}{c|}{ Sterility pollen } \\
\cline { 4 - 9 } & quantity & $\overline{x_{ \pm} \pm S_{\bar{x}}}$ & $\%$ & quantity & $\overline{x_{ \pm} \pm S_{\bar{x}}}$ & $\%$ \\
\hline 1. & Control & 299 & 6653 & $22,25 \pm 0,30$ & 92,0 & 579 & $1,94 \pm 0,09$ & 8,0 \\
\hline 2. & 1 option & 323 & 5566 & $17,23 \pm 0,28^{*}$ & 61,1 & 3538 & $10,95 \pm 0,21^{*}$ & 38,9 \\
\hline 3. & 2 option & 326 & 5551 & $17,03 \pm 0,29^{*}$ & 72,3 & 2130 & $6,53 \pm 0,21^{*}$ & 27,7 \\
\hline
\end{tabular}

Note: $*$ - differences from control are significant at $\mathrm{p}<0,001$

In particular, sterility of male gametophyte of plants in the control zone was $8,0 \%$, and in plants growing along highways with different traffic intensity - increased several times. Thus, the number of abortive gametes increased $4,9(\mathrm{p}<0,001)$ times (variant 1$)$ and 3,5 $(\mathrm{p}<0,001)$ times (variant 2$)$ compared to the control. The results obtained indicate that the number of abortive pollen grains in A. hippocastanum L. from the zone with medium contamination level is higher than in the zone with high contamination level, characterized by more intensive traffic and, as a consequence, higher contamination level. Apparently, this phenomenon can be a consequence of the fact that the generative system of these plants reacts to air pollution when reaching a certain critical level of pollutants, regardless of their concentration. Thus, the pollutants contained in the emissions of vehicles have a pronounced negative impact on the male generative system of the surveyed plants, manifested in increased production of abortive pollen. In this regard, the indicator of reduced production of fertile pollen grains can be used in the system of environmental monitoring of environmental objects experiencing different degrees of technogenic pressure.

Researches of the morphology of sterile pollen (palynomorphological analysis) produced by the generative organs of plants growing along highways with different intensity of traffic, has identified a number of phenotypic disorders: fine (degenerated) pollen, large and narrow (stick-shaped). And the number of phenotypic disorders of male gametophyte reliably increased in comparison with the control zone. Palynomorphological evaluation of sterile pollen grains is presented in Table 2.

Table 2. Comparative indicators of the phenotype of sterile pollen grains of plants growing in the control zone and along motorways with different traffic intensity

\begin{tabular}{|c|c|c|c|c|c|c|c|}
\hline \multirow[b]{2}{*}{ № } & \multirow[b]{2}{*}{$\begin{array}{c}\text { Version } \\
\text { of the } \\
\text { study }\end{array}$} & \multicolumn{6}{|c|}{ Morphological structure of pollen grains } \\
\hline & & 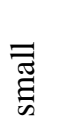 & $\bar{x} \pm S_{\bar{x}}$ & $\begin{array}{l}\stackrel{0}{0} \\
\text { ప్ }\end{array}$ & $\bar{x} \pm S_{\bar{x}}$ & 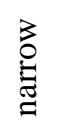 & $\bar{x} \pm S_{\bar{x}}$ \\
\hline 1. & Control & 38 & $0,13 \pm 0,03$ & 55 & $0,18 \pm 0,03$ & 34 & $0,11 \pm 0,02$ \\
\hline 2. & 1 option & 570 & $1,76 \pm 0,19 * * *$ & 462 & $1,43 \pm 0,15^{* * *}$ & 299 & $0,92 \pm 0,10 * * *$ \\
\hline 3. & 2 option & 240 & $0,74 \pm 0,09 * *$ & 319 & $0,98 \pm 0,11^{* * *}$ & 202 & $0,62 \pm 0,07 * * *$ \\
\hline
\end{tabular}

Note: Differences from the control are significant when* $-\mathrm{p}<0,1$; ${ }^{* *}-\mathrm{p}<0,05 ;{ }^{* * *}-\mathrm{p}<0,001$ (tst $_{\mathrm{st}}$ $=2,0-2,6-3,3)$ 
Study of the phenotype of pollen grains A. hippocastanum L. showed that the main disturbance in the formation of male gametes are elongated ellipsoid sterile pollen grains (Fig. 1).

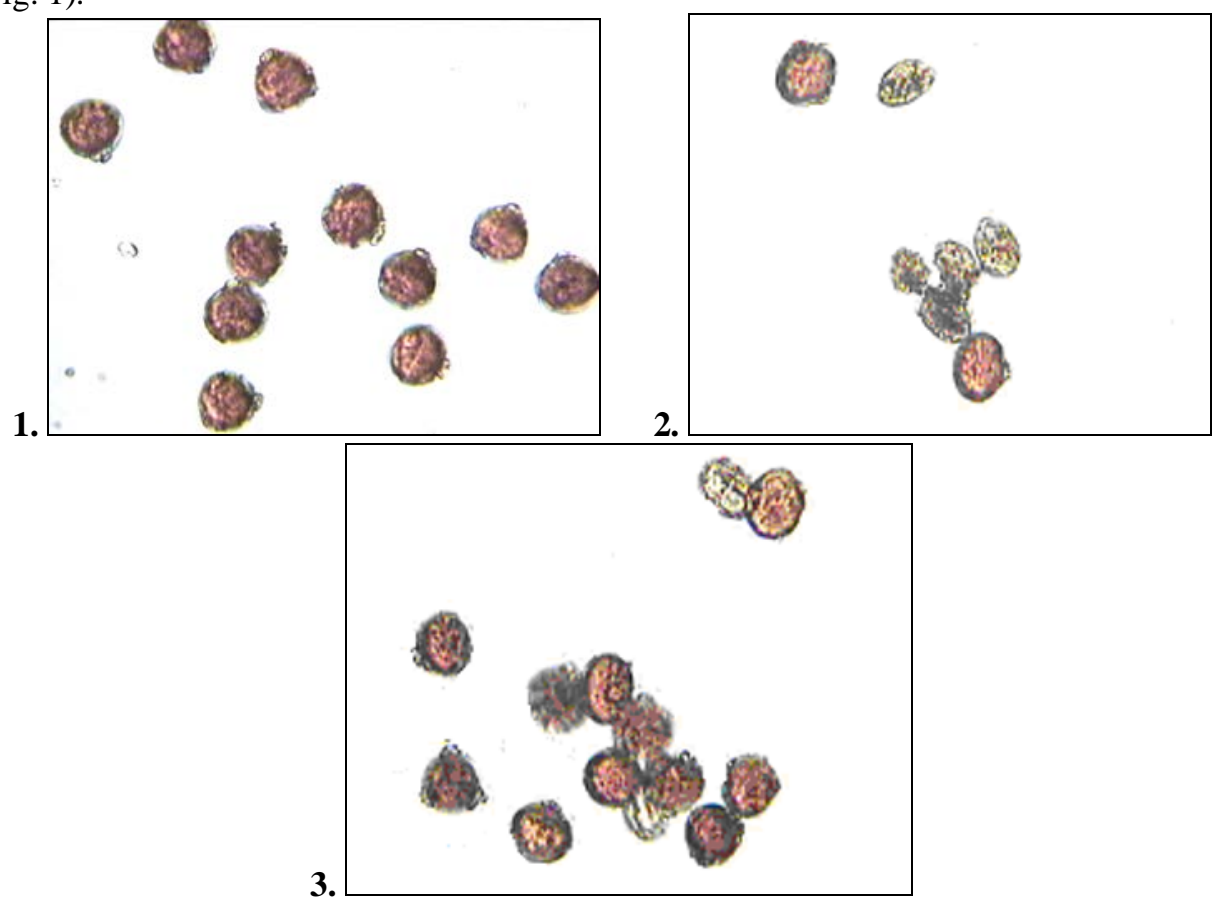

Fig. 1. Male gametophyte Aesculus hippocastanum L. (fertile pollen grains are colored dark, sterile - colorless): 1. - control zone; 2. - zone of heavy traffic; 3. - very heavy traffic.

The results of the palynomorphological evaluation of sterile pollen grains indicate that the main types of microsporogenesis disturbances in the control zone populations were production of fine, coarse and sticky pollen in almost equal amounts. In the zone of average pollution level statistically reliable increase in fine pollen was found. The formation of this type of pollen occurs in the early stages of microsporogenesis during the formation of microspores and gametes with various damages are eliminated in the early stages of their development. In an area with very high road traffic loads, the production of large abortive pollen has increased.

Violation of shape and size of pollen grains can be a result of genetic changes occurring during microsporogenesis. Changes in the genes responsible for gametes morphology lead to various anomalies, in particular narrow or stick-shaped pollen grains. Perhaps this phenomenon is due to the genotoxic effect of pollutants on the male generative system and the microsporogenesis processes taking place in it. All physiological processes in the body are interconnected and genetically determined, so the consequence of genotype disorder is a phenotypic manifestation in the form of underdeveloped pollen with various deviations from the norm. Thus, it is possible to come to the conclusion about mutagenic effect of environmental factors by the degree of damage of male gametes, formed by generative organs of plant organisms, which are in the conditions of technogenic stress.

Therefore, as the road load increases, the production of pollen with various disorders has increased, which may be the result of the modifying effect of polluetants on male gametophyte $A$. hippocastanum L. This phenomenon may indicate the vulnerability of early 
stages of microsporogenesis to high levels of contamination of the roadside zone of highways.

At the same time, we calculated the fertile pollen grain to sterile (F/S) ratio, which characterizes the sensitivity of plant reproductive organs to anthropogenic pollution, and gave the following results (Table 2). This indicator decreased dramatically in populations growing in the studied areas. However, an excess of this indicator was found in the first version of the study as compared to the second one. Thus, in the populations of $A$. hippocastanum L. this indicator decreased in the first variant of the study by 16,5 times, in the second - by 9,2 times, respectively, in comparison with the control variant.

In the conducted study it was found that the populations of plants growing in the roadside zone of highways with medium and high load, recorded a reliable increase in sterile pollen production. Calculation of the sterility index (IS) for all variants of the study allowed concluding that the male generative system of the studied plants reacts to aerotechnogenic pollution in a mixed way. The populations of A. hippocastanum L. had an increased production of abortive pollen in the zone of medium contamination.

Plant organism characterized by increased production of sterile pollen grains in areas of medium contamination can be used for their mapping.

Ranking of the obtained data on EC10-90 classification [10]: initial, effective and sublethal content of toxic pollutants concentrations in the studied areas - respectively, EC10, EC50 and EC90, where inhibition of fertile pollen production by generative organs of the studied plants by 10, 50 and $90 \%$ was observed in comparison with control, allowed to establish that in the studied areas emissions of vehicles had an effective or average toxic effect on the organs of the male generative system of A. hippocastanum L.

\section{Conclusions}

1. The results of the study show that in areas of intensive traffic there is an increased level of production of abortive pollen.

2. Plant populations increasing the formation of damaged gametes with increasing anthropogenic load on phytocoenoses can be used for phytoindication of the environmental pollution degree.

3. In areas with heavy traffic, pollutants have an average toxic effect on the gametogenesis of Aesculus hippocastanum L.

4. The quality and degree of damage to the pollen zone formed by plants can serve as a bio-test of the mutagenic effect of environmental factors that have a modifying effect on male gametophyte of higher plants.

\section{References}

1. R.S. Lavado, M.B. Rodriguez, J.D. Scheiner, M.A. Taboada, G. Rubio, R. Alvarez, M. Alconada, M.S. Zubillaga, Commun. Soil Sci. and Plant Anal., Heavy metals in soils of Argentina: Comparison between urban and agricultural soils, 29 (11-14), pp. 19131917 (1998).

2. V.L. Bocharov, Yu.V., Ivanov Tomsk State University Journal. Ser. Geol., Ecological and geochemical methods for assessing the atmospheric pollution of small cities (on the example of the city of Livny, Orel region), 4, pp. 137-145 (1997). (in Russian)

3. L.I. Belykh, V.A. Seryshev, E.E. Penzina, V.A. Belogolova, V.A. Khutyoryansky, Soil Science, The content of benzo(a)pyrene in the soils of some regions of the Irkutsk region, 3, pp. 334-341 (1997). (in Russian)

4. V.N. Ivanov, V.K. Storchevus, Ecology and motorization, 128 p. (1990). (in Russian) 
5. E.E. Ibragimova, Crimean ecosystems, their optimization and protection, Palinomorphological assessment of technogenic chemical pollution of the environment by the example of pollen from Armeniaca vulgaris, 17, pp. 211-217 (2007). (in Russian)

6. V.P. Bannikova, O.A. Khvedynich, Fundamentals of plant embryology, 164 p. (1981).

7. T.S. Fadeeva, S.P. Sosnikhina, N.M. Irkaeva, Comparative plant genetics, 248 p. (1980). (in Russian)

8. Z.P. Pausheva, Workshop on plant cytology, 304 p. (1980). (in Russian)

9. D.V. Balichieva, E.E. Ibragimova, D.E. Emirova, Patent 32513 of Ukraine for a utility model, Method for determining palytotoxicity of man-caused chemical pollutants, 10 (2008). (in Ukrainian)

10. T.I. Evseeva, T.A. Maystrenko, S.A. Geraskin, E.S. Belykh, E.V Kazakova, Cytology and genetics, Toxic and cytogenetic effects induced in A. cepa by low concentrations of Cd and 232Th, 5, pp. 73-80, (2005). (in Russian) 